\title{
AUTONOMIA E ESCLARECIMENTO EM PAULO FREIRE: QUESTÕES NECESSÁRIAS À EDUCAÇÃO PAUTADA NA PRÁTICA DA LIBERDADE
}

\author{
AUTONOMY AND CLARIFICATION IN PAULO FREIRE: \\ NECESSARY ISSUES FOR EDUCATION BASED ON THE PRACTICE OF FREEDOM
}

\author{
Ana Maria Honorato Borges ${ }^{1}$ \\ Euzilene Ferreira de Rezende ${ }^{2}$ \\ Ludimila Lemes Arruda Ferreira ${ }^{3}$
}

RESUMO: O presente artigo tem por objetivo apresentar reflexões sobre autonomia e esclarecimento. Estas duas expressões são essenciais no contexto da educação contemporânea, haja visto que para o ser humano se tornar um ser social e aparentemente livre, ele carece de ser educado e ter consciência do quanto vale a pena a sua independência. Neste sentido, a discussão proposta é relevante num momento em que se vive muito mais a heteronomia do que a autonomia propriamente dita. Autores como Carlos Rodrigues Brandão, Norberto Bobbio, Immanuel Kant e outros foram utilizados neste estudo, porém a ênfase será dada a Paulo Freire. Em Freire, autor considerado como um dos influenciadores do movimento chamado Pedagogia Crítica e um dos mais célebres educadores do Brasil, se encontra o cerne da autonomia, em especial, para aqueles alunos que se matriculam nas instituições de ensino somente na vida adulta. Para ele, a escolarização é o ponto de partida para a conquista do próprio eu, pois ao se autoidentificar o aluno consegue se situar na sociedade de maneira analítica e negar a tudo o que conduz a opressão, evoluindo assim à construção do seu pensamento crítico. Para discutir o referido tema foi realizada uma revisão da literatura, principalmente nas obras Pedagogia do Oprimido e Pedagogia da Autonomia que tratam especificamente de autonomia a partir da condição de opressão. Essas e outras obras do autor trazem contribuições para compreender a importância de se construir uma educação pautada na liberdade, no respeito e na ética, pois só assim os indivíduos serão capazes de perceber e envidar esforços na luta contra as ideologias das classes dominantes e buscarem uma sociedade mais justa e digna para todos.

Palavras-chave: Autonomia. Educação. Esclarecimento. Oprimido.

ABSTRACT: The purpose of this article is to present reflections on autonomy and clarification. These two terms are essential to the environment of contemporary education, given that for the human being to become a social and seemingly free being, he needs to be educated and aware of how much his independence is worth. In this sense, the proposed discussion is relevant at a time when heteronomy is much more experienced than autonomy itself. Authors such as Carlos Rodrigues Brandão, Norberto Bobbio, Immanuel Kant and others were referenced in this study, but the

\footnotetext{
${ }^{1}$ Mestranda em Educação - FACMAIS - Faculdade de Inhumas/GO - E-mail: pleiades.anaborges@gmail.com. ${ }^{2}$ Mestranda em Educação - FACMAIS - Faculdade de Inhumas/GO - E-mail: euzilenerezende@hotmail.com. 3 Mestranda em Educação - FACMAIS - Faculdade de Inhumas/GO - E-mail: ludimilalemesarruda@gmail.com.
} 
emphasis is on Paulo Freire. In Freire's work, considered one of the influencers of the movement called Critical Pedagogy and one of the most celebrated educators in Brazil, the core of autonomy is found, especially for those students who enroll in educational institutions only in adulthood. To Freire, schooling is the starting point for the conquest of self, because by self-identifying the student can situate himself in society in an analytical way and deny everything that leads to oppression, thus evolving to the construction of his critical thinking. To discuss the proposed theme, a literature review was carried out mainly in the works Pedagogia do Oprimido and Pedagogia da Autonomia, which specifically deal with autonomy based on the condition of oppression. These and other works by the author highlight the importance of building an education based on freedom, respect, and ethics because only this way individuals will be able to perceive and put efforts into the struggle against the dominant classes ideologies and seek a fairer and more dignified society for all.

Keywords: Autonomy. Education. Clarification. Oppressed.

\section{INTRODUÇÃO}

O presente artigo apresenta uma reflexão em torno da autonomia e do esclarecimento a partir de Paulo Freire. Ao versar sobre autonomia Paulo Freire lança mão da liberdade como pressuposto fundamental, pois ela não se encontra destituída da autonomia.

A sociedade contemporânea vivencia um período crítico na educação não somente por questões ideológicas, mas principalmente porque há uma incerteza por parte do próprio governo em relação a quem representa a educação no Brasil, já que a ausência de uma política educacional mais robusta, assim como as constantes trocas de representantes da pasta requerem um olhar mais reflexivo da sociedade sobre o papel que a educação ocupa nesse cenário.

A mudança necessária precisa partir da sociedade que ao invés de assistir passiva a tudo o que está acontecendo, deve cobrar por melhorias e pela efetivação de políticas que sejam favoráveis ao desenvolvimento da educação, sendo esse o ponto de partida para situá-la num lugar mais próximo dos países que se destacam nesse setor há anos. Todo esse processo requer uma consciência crítica que se dá a partir da autonomia.

Ao compreender a relevância da autonomia, bem como vivenciá-la, o estudante consegue se situar no meio social, pois embora esteja inserido num contexto marcado por ideologias, ele consegue vislumbrar outro cenário a partir de uma luta constante que se dá principalmente, por meio da educação. Ele tem consciência de que existe um sistema que oprime e segrega, mas somente se adere a ele quem não possui esclarecimento.

Para discorrer o assunto proposto, foi realizada uma revisão de literatura em obras e artigos de autores que discorrem a educação como a prática da liberdade e dentre eles estão Carlos Rodrigues Brandão, Bobbio, e em especial, Paulo Freire, cuja análise foi realizada em obras reconhecidas do 
autor como: Pedagogia da Autonomia, Pedagogia do Oprimido e Pedagogia da Esperança. Além destes, também foi mencionado Immanuel Kant cujas descrições foram fundamentais para compreender o papel da autonomia na formação do sujeito contemporâneo.

\section{Autonomia como fruto do esclarecimento}

O termo autonomia vem de autós que significa por si próprio ou de si mesmo. Uma pessoa que tem competência para governar a si mesma é autônoma. Pode também ser entendido como direito ou faculdade de se reger (uma ação) por leis próprias, liberdade ou independência moral ou intelectual, propriedade pela qual os seres humanos podem escolher os caminhos que regem sua conduta.

De acordo com Pitano e Ghiggi (2009, p. 83):

Tendo por base a tradição filosófica, a autonomia tem sua origem fortemente marcada por Kant, o qual procurou designar a independência da vontade em relação a todo o desejo ou objeto de desejo e a capacidade dessa mesma vontade do indivíduo para determinar-se, sempre em conformidade com uma lei própria, a da razão. Kant contrapõe a autonomia à heteronomia pela qual a vontade é determinada pelos objetos da faculdade de desejar. Da mesma forma, os ideais morais de felicidade ou de perfeição supõem a heteronomia da vontade, supõem que ela seja determinada pelo desejo de alcançá-los e não por uma lei sua e própria. A independência da vontade em relação a qualquer objeto desejado é a liberdade no sentido negativo, ao passo que a sua legislação própria (como razão prática) é a liberdade no sentido positivo. A lei moral não exprime nada mais do que a autonomia da razão prática, isto é, da liberdade.

As colocações de Kant acerca da autonomia remetem à subjetividade, pois cada indivíduo é quem responde por si mesmo e pode escolher o que considera melhor para sua vida. O contrário disso é comodismo e dominação.

\section{Autonomia em Paulo Freire}

Tratar de autonomia sob a perspectiva de Paulo Freire é uma possibilidade de enxergar com lentes ampliadas de que maneira o autor a concebe, pois, em toda a literatura deixada por ele é possível observar o desejo em construir uma educação equânime, cujos sujeitos sejam capazes de transformar a realidade a partir de suas vivências rejeitando a tudo que conduz a opressão.

Acerca disso Pitano e Ghiggi (2009, p. 84) contribuem para essa reflexão:

Paulo Freire, no que lhe concerne, não se detém no desenvolvimento de um conceito de autonomia, a 'priori', anterior ao que a experiência refletida torna possível. A sua reflexão está presente nas incursões que vai fazendo a respeito de "saberes necessários à prática educativa", conforme reflexão exposta em Pedagogia da Autonomia (1997) e outros escritos. Mais ainda: Freire intitula Pedagogia da 
Autonomia a uma de suas últimas e principais obras refletindo exaustivamente temas como autoridade, liberdade, competência, ética, etc. O que leva Freire a apresentar, assim, a sua reflexão sobre autonomia? É, pensamos, a própria compreensão de autonomia que o faz seguir o caminho da discussão sobre ética, competência e autoridade.

Ressalta-se que o desejo de Paulo Freire era proporcionar ao indivíduo a oportunidade de pensar por si mesmo, a partir da formação de um senso analítico, crítico e transformador. Segundo ele, a grande preocupação do homem com os problemas que o rodeia, faz com que se torne alerta a assuntos de fundamental importância como a educação como prática para a liberdade, dentro de um contexto histórico de busca pela humanização, consciente da sua realidade, de sua objetiva luta contra a tirania opressora exercida por outros homens. Ao mesmo tempo, em que lutam contra a opressão, são capazes de oprimir, no entanto, deveriam estar continuamente buscando por um trabalho livre, pela desalienação e sua afirmação como ser.

De acordo com Freire (1987) a desumanização mesmo sendo um fato histórico, não é destino dado, mas resultado de uma "ordem" injusta que gera a violência dos opressores. Sentindo-se injustiçado pela opressão, os oprimidos lutam contra quem os oprimem, enquanto os opressores também se sentem oprimidos, formando assim uma cadeia de opressores e oprimidos em busca da libertação.

Os opressores por sua vez exploram e violentam em razão do seu poder não tendo forças para libertar nem ao outro, nem a si próprio, tornando assim uma falsa generosidade. $O$ autor diz ser necessário uma "pedagogia que faça da opressão e de suas causas objeto de reflexão dos oprimidos, de que resultará o seu engajamento necessário na luta por sua libertação, em que esta pedagogia se fará e refará" (FREIRE, 1987, p. 17).

As breves considerações pautadas na obra Pedagogia do Oprimido sinalizam o desejo de autor em ressaltar que sendo oprimido, o sujeito se sente sem forças para se livrar de tal estado. Ao permanecer assim ele se insere num estado de letargia.

Essa condição também pode ser reconhecida naqueles que tem o ofício de ensinar. Infelizmente é muito comum encontrar professores que não vão além, ficam estacionados em suas próprias ideias e concepções. Não querem mudar, resistem em permanecer com a mesma metodologia e enquanto isso, os alunos perdem a oportunidade também de despertarem seu senso crítico e enxergarem outra maneira de enfrentar o mundo.

Na visão de Paulo Freire (1987) o homem "novo", no caso dos oprimidos, é ele mesmo, tornando-se opressores de outros, com uma visão individualista, pois a sua aderência ao opressor não lhes possibilita consciência dele como pessoa, nem de sua classe de oprimidos. Os oprimidos têm 
medo de assumir a liberdade e já os opressores sentem medo de não poder mais oprimir ao perder a liberdade de fazê-lo. Por essa razão, a libertação é comparada a um parto, o qual pode ser entendido parto como o comodismo e isso pode ser verificado quando é apresentada aos professores uma nova maneira de ministrar as aulas, como, por exemplo, utilizando das tecnologias da informação, que são excelentes ferramentas, mas que para sua utilização demandam um conhecimento prévio ou tempo e dedicação para aprender, e isso acabar por gerar muita resistência.

Ao reconhecer a importância de sair de onde se está e lançar-se aos novos desafios, tem-se, portanto, um processo de libertação, pois, ao mesmo tempo, essa atitude gerará críticas daqueles que optam por permanecer no mesmo lugar. Para Freire a educação tem o poder de emancipar aquelas pessoas que não tiveram oportunidades de adquirir conhecimentos na idade própria. E o educador passou a ser o ponto de partida do trabalho pedagógico.

Ao tratar de esclarecimento Freire destaca que o processo de aprendizagem é lento e que às vezes pode não representar um objetivo para a pessoa, caso ela não se interesse e, nessa altura perde a oportunidade de sair de si mesmo, como, por exemplo, no Mito da caverna de Platão, cuja saída permite ver a luz e sair tanto do comodismo, quanto da ignorância. A caverna simboliza o mundo, pois nos apresenta imagens que não representam a realidade. Só é possível conhecer a realidade, quando nos libertamos destas influências culturais e sociais, ou seja, quando saímos da caverna.

Na obra Pedagogia da Autonomia, Paulo Freire (1996) intensifica a discussão, pois para o autor a grande emancipação do ser humano começa na escola, quando a partir do contato com textos, conteúdos, enfim, com a cultura, ele adquire outra visão de mundo, pois a missão do educador é proporcionar ao educando a busca incessante pela troca de conhecimentos e experiências, amparados pelo processo da intercomunicação, onde todos são em simultâneo, instrutores e aprendizes.

A grande tarefa do sujeito que pensa certo não é transferir, depositar, oferecer, doar ao outro, tomado como paciente de seu pensar, a inteligibilidade das coisas, dos fatos, dos conceitos. A tarefa coerente do educador que pensa certo é, exercendo como ser humano a irrecusável prática de inteligir, desafiar o educando com quem se comunica e a quem comunica, produzir sua compreensão do que vem sendo comunicado. Não há inteligibilidade que não seja comunicação e intercomunicação e que não se funde na dialogicidade. O pensar certo por isso é dialógico e não polêmico (FREIRE, 1996, p. 2I).

Sobre ensinar estimulando reflexão crítica sobre a prática, Freire (1996) mostra que é pensando reflexivamente a prática de hoje ou de ontem que se torna possível pensar o presente e futuro. Na visão de Freire, quanto mais o sujeito se assume e se percebe a partir de suas ações, mais ele se torna capaz de modificar-se. 
Ao colocar a questão do reconhecimento da identidade cultural ele afirma que o respeito é absolutamente fundamental na prática educativa progressista. Ele discute sobre o ato de ensinar como sendo algo dinâmico e não apenas como o ato de transferir conhecimentos, isto é, o professor deve criar possibilidades para a sua própria produção e (re)construção dos saberes.

O professor deve ensinar que o conhecimento é inacabado. A falta da busca pelo conhecimento é um problema social. O ser humano às vezes se perde nesta busca deixando de ser ético. Sobre isso, Freire cita várias vezes a importância de se conhecer a cada dia: "Gosto de ser homem, de ser gente, porque sei que a minha passagem pelo mundo não é predeterminada, preestabelecida. Que o meu "destino" não é um dado, mas algo que precisa ser feito e de cuja responsabilidade não posso me eximir" (FREIRE, 1996, p. 30).

Nesse sentido, o educando é conduzido a pensar sobre o mundo que o cerca e sobre os processos de dominação que lhe são impostos. Hoje são muitas as dominações que requerem esclarecimento. A começar pela mídia que inculca na mente de crianças e jovens exatamente aquilo que a sociedade prega e que muitas vezes, não condiz com a realidade. Por outro lado, o próprio Estado também conduz o sistema a partir de uma ideologia e disso decorre a importância da educação. “[...] Educação enquanto ato de conhecimento, não só de conteúdos, mas da razão de ser dos fatos econômicos, sociais, políticos, ideológicos, históricos" (FREIRE, 1992, p. 53). Ensinar requer identificar a educação como sendo dialógica. É necessário saber mostrar isso aos educandos e analisar esse processo com um olhar crítico, o qual é viabilizado pelo diálogo. Ao se tornar disponível permanentemente à vida, o sujeito consegue compreender o mundo de maneira crítica, amorosa e com desejo que a cada dia seja possível construir uma sociedade melhor.

A prática pedagógica mediada a partir do diálogo, da discussão e da abertura para se compreender as diferentes maneiras de conceber a realidade permite que o aluno também perceba que a educação é ideológica e que por isso ele é obrigado a obedecer ao que é imposto. Pelo contrário, quanto mais se nega posturas autoritárias e ideológicas, mas se contribui para a construção de uma sociedade voltada para a liberdade e equidade. Quando o sujeito apenas aceita as imposições sem questionar, ao invés de ter desenvolvido nele a autonomia, desenvolveu a heteronomia.

\section{Heteronomia em contraposição a autonomia}

Entende-se por heteronomia o processo pelo qual uma pessoa concorda com algo mesmo contra sua vontade e obedece passivamente sem questionar seja por conformismo, seja por medo das consequências. Para Bobbio (1997) a heteronomia é quando a vontade busca a lei, não em si mesma, mas em outro lugar, exterior a si próprio. 
Paulo Freire se posiciona contra a heteronomia na obra Pedagogia do Oprimido, onde o autor ressalta que somente a educação será capaz de libertar o oprimido. Zatti (2007) assevera tal posicionamento freiriano:

A proibição de ser mais estabelecida pela opressão é em si mesma uma violência. A resposta dos oprimidos a essa violência deve ser no sentido de buscar o direito de ser, sua luta é no sentido de fazer-se homem. Nas nossas sociedades, o processo de violência passa de geração em geração, o que vai formando uma consciência possessiva do mundo e dos homens, tudo é transformado em mercadoria, o dinheiro é a medida para tudo e o lucro torna-se o objetivo principal. No momento em que por meio dessa ganância desmedida dispõe da vida de pessoas, tirando-lhes a dignidade e a liberdade, transformando-as em coisa, as legam a situação de heteronomia (ZATTI, 2007, p. 39).

A heteronomia aponta para a dominação que é negada pela pessoa, sem que para tanto, ela tenha coragem de enfrentar as situações adversas e propor mudanças.

Segundo Bresolin (2013), a heteronomia ocorre quando a vontade não se dá a lei a si mesma, mas é sim um impulso estranho que dá a lei. Como consequência o valor moral da ação não reside, portanto, no efeito que dela se espera, mas no modo como a máxima do agir foi determinada.

Tal assertiva pode ser claramente verificada no sistema educacional contemporâneo, no qual as mudanças não surgem dos professores, mas a eles são impostas, como a Base Nacional Comum Curricular (BNCC) ${ }^{4}$ que foi aprovada com propostas nefastas para a educação e mesmo estando conscientes, muitos professores não se manifestaram para que tais ideias não fossem consolidadas, seja por se considerarem impotentes, ou até mesmo, por receio.

Como se pode observar, a capacidade de autorreflexão leva ao esclarecimento e a consequente negação a toda situação que oprime e separa os homens em suas diferentes classes. De acordo com Freire, a liberdade de cada um (autonomia) cresce no confronto com outras liberdades, com outras opções, etc., com as diferenças, em cuja história de "perversão social e de exclusão" exige que se construa elos na busca desperta e utópica de relações sociais dignas para todos.

Freire (1996) ao redundar na questão da autonomia se utiliza de várias metáforas e situações para explicar o quanto os homens se veem acuados quando se sentem dominados e explica que em muitos oprimidos o que atrapalha a libertação é medo de ficar livre e isso não conduz a autonomia. Para ele o medo de ser livre nasce da prescrição, sendo que toda prescrição vem da imposição de uma

\footnotetext{
${ }^{4}$ A BNCC é um documento que visa sistematizar o que é ensinado nas escolas do Brasil inteiro, englobando todas as fases da educação básica, desde a Educação Infantil até o final do Ensino Médio. Trata-se de uma espécie de lista com os objetivos de aprendizagem de cada uma das etapas de sua formação nas áreas de Linguagens, Matemática, Ciências da Natureza e Ciências Humanas. Longe de ser um currículo totalmente fixo, a Base Nacional é uma ferramenta que visa orientar a elaboração do currículo específico de cada escola, sem desconsiderar as particularidades metodológicas, sociais e regionais de cada uma.
} 
pessoa para outra. Por isso ela aliena e faz com que o oprimido, que tem a consciência hospedeira, se sustente nos opressores. Sendo assim, o homem oprimido está na condição de heteronomia. É uma luta que se trava internamente a qual só pode ser combatida a partir da conquista da autonomia do sujeito oprimido.

Nota-se que as colocações de Paulo Freire acerca da autonomia são amplas e envolvem muito mais que o medo de enfrentar situações adversas, pois o homem com toda sua complexidade, ora consegue encarar desafios, ora se acovarda e prefere ficar como expectador para ver o que poderá acontecer.

\section{Autonomia e educação}

A educação é o principal palco onde a autonomia pode de fato se apresentar e se inserir na forma de ser e de pensar das pessoas, pois é ferramenta de libertação. Para compreender como esse processo se dá na educação será preciso reportar à obra Pedagogia da Esperança na qual Freire reafirma a posição assumida em Pedagogia do Oprimido.

Nesta obra o autor enfatiza a importância de re-ver, re-pensar e de re-dizer. Esse processo formado por uma tríade traduz todo o tempo de exilio do autor no Chile cuja permanência lhe rendeu muitas memórias. Toda essa experiência de Freire, assim como dos demais autores e artistas exilados à época da ditadura militar, tem como ponto de partida o pensamento autônomo, processo pelo qual nenhum cidadão poderia passar e nem tampouco manifestar.

Na educação, a autonomia se dá a partir da autorreflexão e do debate. Caso não exista esse espaço, os estudantes tendem a se deixar alienar, sendo esse o propósito do modelo dominante de educação, atual não somente no Brasil, mas em grande parte do mundo.

Nesse sentido, para Freire a educação teria como principal objetivo despertar o caráter crítico e autônomo do aluno, pois é preciso que o discente aprenda a pensar. Tal assertiva é muito importante, já que a educação que se tem ofertado no Brasil retira dele o direito desse exercício.

Um exemplo que se pode dar são os inúmeros discentes que passam pelas escolas atualmente. Existe todo um trabalho previamente elaborado pelo professor, que não raro, é muito bem preparado para ministrar uma aula. Em contrapartida, os alunos se mostram desinteressados, não querem aprender e o resultado são pessoas que são aprovadas para a série seguinte, mas no entanto, não conseguiram desenvolver seu pensamento crítico.

A dificuldade de desenvolver pensamento crítico conduz a heteronomia e leva as pessoas a um estado de estagnação. É o que se vê, por exemplo, em turmas heterogêneos, marcada pela defasagem idade/série no qual muitas vezes o aluno fica ali por dois ou três anos sem se importar 
com o tempo perdido e vai conduzindo esse processo sem refletir, porque se tivesse a compreensão de que a autonomia o tiraria daquele estado, certamente rejeitaria sua própria atitude e lutaria para mudar o seu futuro.

A falta de autonomia leva as pessoas ao treino, porque são incapazes de dizer não e preferem simplesmente obedecer. Segundo Kant (1999), o homem pode ser ou treinado, disciplinado, instruído mecanicamente, ou ser em verdade ilustrado. No campo da educação, os alunos podem ser treinados, ou motivados a desenvolverem suas competências, tanto acadêmicas quanto morais, sendo que essa última os levaria a autonomia, a liberdade.

Freire ilustra essa questão ao colocar no centro das discussões a leitura e escolarização como ponto de partida para a construção da autonomia, afirmando que muitos indivíduos encararam suas trajetórias de vida como uma sina, ou seja, como uma situação imutável. Neste sentido, Vicente Zatti comprova o pensamento freiriano revelando que:

A consciência do oprimido se encontra geralmente dentro de um mundo mágico e mítico, o que faz com que o destino, a sina, a vontade de Deus, sejam postos como causa da opressão. Nesse caso, a causa é vista com caráter mítico, sendo assim, inacessível, inatingível, a mudança torna-se irrealizável e a heteronomia não é superada. Esse "fatalismo" é um dos principais perpetuadores de situações de menoridade, de opressão, de heteronomia, pois leva ao imobilismo (ZATTI, 2007, p. 39).

O imobilismo e a aceitação conduzem os sujeitos à exclusão e a construção de um pensamento de que "é assim mesmo" e de que "não adianta lutar". Dentro desses grupos vez ou outra aparecem aqueles que não aceitam e vão à luta mesmo diante das adversidades.

Kant (1999) afirma que os animais são treinados assim como o homem também pode ser, porém, só o treinamento não produz conhecimento. Só pode ser utilizado de modo sintético e que por isso não contribui para a interação e nem tampouco faz a mediação da natureza e da cultura e muito menos humaniza.

Contudo, o que tem percebido é que o treinamento é um dos métodos mais utilizados na educação brasileira. Essa forma nefasta de conduzir as coisas mesmo que de maneira sutil e legalizada, tem sido responsável pelo fracasso crescente de jovens e crianças, que ao serem dominadas e treinadas, pouco tem para contribuir e quando se veem diante da análise de um texto ou situação, “mergulham em águas rasas" pela simples incapacidade de emitir uma opinião de maneira crítica e consciente.

Acerca disso, Zatti (2007, p. 34) contribui para a reflexão:

Como a educação consiste em exercer uma espécie de imposição de limites sobre o estado da natureza de modo a que a liberdade possa se expandir abrindo espaço para 
à cultura, Kant busca um conceito sintético que concilie essa passagem e os dois conceitos de liberdade subsumidos nela, liberdade como espontaneidade e liberdade como autonomia. Indica esse conceito sintético no conceito de trabalho.

Ao discorrer sobre o assunto, Kant reforça que o trabalho supõe a necessidade e a submissão a outra pessoa, o peso do mundo, contudo, é também liberdade. A partir dele o homem descobre a si mesmo e aos outros. Desse modo, liberdade e obediência estão associadas de maneira sintética a noção de trabalho em face da passagem da natureza à cultura.

Eis aí uma questão que pode causar prazer e sofrimento: o trabalho. Acerca disso, várias vertentes podem ser analisadas. A primeira é a "privação" do jovem para trabalhar, porque o Estatuto da Criança e do Adolescente (ECA) em nome de uma proteção integral, não permite que o adolescente trabalhe. É claro que a ideia de coibir a exploração da mão de obra infantil é louvável, contudo, há exceções e enquanto não trabalham, muitos dos jovens estão nas ruas se drogando, roubando, prostituindo e daí surge um questionamento, isso é "legal"?

A outra questão é o desemprego estrutural que marca o país nos últimos anos e que exclui milhares de pessoas do mercado de trabalho. Nesses dois casos, a falta de trabalho não somente retira a dignidade, mas mantém o homem contemporâneo (em especial o brasileiro) num estado de inércia em razão do discurso que prevalece acerca da crise social em todos os sentidos.

Nesse ponto é necessário recorrer não somente a Freire, mas a todos aqueles que discorrem o tema e veem na educação uma fonte de transformação e de libertação.

Em Carlos Rodrigues Brandão ( $\mathrm{O}$ que é educação) estão expressos todos esses desejos, pois para esse autor a educação é esperança.

Se a educação é determinada fora do poder de controle comunitário dos seus praticantes educandos e educadores diretos, por que participar dela, da educação que existe no sistema escolar criado e controlado por um sistema político dominante? Se na sociedade desigual ela reproduz e consagra a desigualdade social, deixando no limite inferior de seu mundo os que são para ficar no limite inferior do mundo do trabalho (os operários e filhos de operários), e permitindo que minorias reduzidas cheguem ao seu limite superior, por que acreditar ainda na educação? Se ela pensa e faz pensarem o oposto do que é na prática do seu dia a dia, por que não forçar o poder de pensar e colocar em prática outra educação? (BRANDÃO, 2007, p. 98)

Os questionamentos do autor conduzem à reflexão, porque se a educação é tudo o que foi colocado, então, por que continuar insistindo nesse sistema no decorrer de toda sua existência? A resposta está exatamente naquilo que Paulo Freire, assim como tantos outros pensam sobre a educação de modo geral, visto que ela é campo de contradições. Ou seja, ao mesmo tempo, em que 
para uns ela é imposta e o sujeito aceita (ocorrendo aí uma heteronomia), para outros ela é espaço de discussões e reflexões, e desse processo decorre a suma importância da filosofia.

Onde surgem interesses desiguais e, depois, antagônicos, o processo educativo, que era unitário, torna-se partido, e depois, imposto. Há educações desiguais para classes desiguais; há interesses divergentes sobre a educação, há controladores. Grupos desiguais não só participam desigualmente da educação - dos nobres, dos funcionários, dos artesãos - como são também por ela destinados desigualmente ao trabalho: para dirigir, para executar, para produzir (BRANDÃO, 2007, p. I03).

Também é por meio da educação e principalmente de argumentos fundamentados que será possível abrir discussões para se questionar os princípios fechados do Estatuto da Criança e do Adolescente, pois é preciso sim, proteger crianças e adolescentes do trabalho precoce e escravo, mas o trabalho dignifica e engrandece o homem.

Outra, melhor seria: porque a educação sobrevive aos sistemas e, se em um ela serve à reprodução da desigualdade e à difusão de ideias que legitimam a opressão, em outro pode servir à criação da igualdade entre os homens e à pregação da liberdade. Outra ainda poderia ser: porque a educação existe de mais modos do que se pensa e, aqui mesmo, alguns deles podem servir ao trabalho de construir outro tipo de mundo (BRANDÃ O, 2007, p. 99).

Ao analisar as possíveis respostas apresentadas pelo próprio Brandão, nota-se que a educação é esperança e por isso ela sobrevive há tanto tempo. Enquanto promotora de novos tempos, é também na educação que se diz não a heteronomia e sim a autonomia, que é fonte de liberdade e rejeição à opressão.

Esta é a esperança que se pode ter na educação. Desesperar da ilusão de que todos os seus avanços e melhoras dependem apenas de seu desenvolvimento tecnológico. Acreditar que o ato humano de educar existe tanto no trabalho pedagógico que ensina na escola quanto no ato político que luta na rua por um outro tipo de escola, para outro tipo de mundo (BRANDÃO, 2007, p. 99).

Ou seja, a educação se torna esperança quando ela sinaliza ser possível mudar a realidade caótica que nos é apresentada. Enquanto o sistema insiste em formatar currículos, impor modelos de avaliação, propor a retirada de disciplinas essenciais como Filosofia, Sociologia e Educação Física, é possível pensar o contrário e lutar para que esse processo não aconteça.

A resistência à toda forma de opressão, direciona o homem para sua libertação, para sua autonomia e para sua capacidade de olhar sob outras lentes e dizer que mesmo diante do caos é possível construir um novo futuro.

É papel do educador oportunizar a promoção da autonomia, o crescimento pessoal e a cidadania, que é também função da escola. Paulo Freire (I996, p. I2), aborda outra relação importante: a cumplicidade existente entre o ato de ensinar e aprender. Segundo ele, "Quem ensina aprende ao 
ensinar e quem aprende ensina ao aprender." $\mathrm{O}$ ato de educar é muito mais amplo que qualquer definição etimológica.

Ao formar o ser humano para a vida, a educação é capaz, também, de interferir no modo de pensar dele. Nessa perspectiva, ela pode contribuir para a formação dos indivíduos em todos os sentidos, sendo a essência para a construção de um pensamento analítico, crítico e transformador.

\section{Considerações finais}

O texto apresenta de maneira breve os conceitos de autonomia e esclarecimento a partir do pensamento de Paulo Freire e de outros autores que contribuíram para essa discussão. Procurou-se situar a autonomia como algo que é próprio de cada ser humano, já que cada um concebe a realidade de uma maneira distinta (sob suas próprias lentes), contudo, nem todos a desenvolve, principalmente na sociedade contemporânea, em que consistir é mais fácil do que resistir e desse processo pode resultar a zona de conforto ou confronto.

Tanto Freire quanto os demais autores mencionados, consideram que a autonomia surge do pensamento crítico que por sua vez é fruto do esclarecimento. Os estudos dos trabalhos destes autores mostram que, a emancipação é fruto da autonomia, a qual é alcançada essencialmente negando a opressão e dominação postos pela sociedade de modo geral.

Autonomia e esclarecimento são essenciais para se vislumbrar uma educação pautada na liberdade, onde educadores e educandos se tornam sujeitos de um processo contínuo de troca de saberes e se colocam dispostos numa via em que o conhecimento é um protagonista mutante, capaz de transformar a todos e possibilitar o distanciamento da heteronomia, através de uma relação dinâmica, dialógica e crítica.

A consciência do inacabamento em Freire é requisito indispensável à construção desta autonomia. Essa dimensão permite ao ser humano inserir-se numa busca de construir e desconstruir a sua história, sendo que esse é um processo desafiador, capaz de provocar no sujeito a necessária tomada de atitude diante do mundo ao qual ele pertence.

\section{Referências}

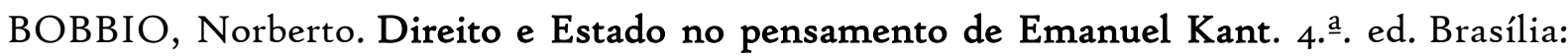
$\mathrm{UnB}, 1997$.

BRANDÃO, Carlos Rodrigues. O que é educação. I⿳âa. ed. São Paulo: Brasiliense, 2007. BRESOLIN, Keberson. Autonomia versus heteronomia: o princípio da moral em Kant e Levinas. Conjectura: Filosofia e Educação, Caxias do Sul, v. I8, n. 3, p. 166-ı83, 2013. FREIRE, Paulo. Pedagogia do Oprimido. 17ª ed. Rio de Janeiro: Paz e Terra, 1987. 
Pedagogia da Esperança: um reencontro com a Pedagogia do oprimido. I⿳亠丷a. ed. Rio de Janeiro: Paz e Terra, 1992.

Pedagogia da Autonomia: saberes necessários à prática educativa. 25ํ. ed. São Paulo: Paz e Terra, 1996.

KANT, Immanuel. Sobre a Pedagogia. Tradução de Francisco Cock Fontanella. $2^{\underline{a}}$. ed. Piracicaba: Unimep, 1999.

PITANO, S. de C.; GHIGGI, G. Autoridade e liberdade na práxis educativa Paulo Freire e o conceito de autonomia. Saberes, Natal, v. 2, n. 3, p. 80-93, 2009.

ZATTI, Vicente. Autonomia e Educação em Immanuel Kant e Paulo Freire. Porto Alegre: EdiPUCRS, 2007. 